Brief Report

\title{
Two Cycad Species Affect the Carbon, Nitrogen, and Phosphorus Content of Soils
}

\author{
Thomas E. Marler $1, *$ (1) and Michael Calonje ${ }^{2}$ \\ 1 Western Pacific Tropical Research Center, University of Guam, UOG Station, Mangilao, Guam 96923, USA \\ 2 Montgomery Botanical Center, 11901 Old Cutler Road, Coral Gables, FL 33156, USA; \\ michaelc@montgomerybotanical.org \\ * Correspondence: marler.uog@gmail.com
}

Received: 28 February 2020; Accepted: 30 March 2020; Published: 10 April 2020

\begin{abstract}
The influences of Cycas micronesica and Zamia integrifolia plants on soil chemistry were determined in Tinian and Florida in order to more fully understand how cycad plants affect the environments in which they grow. The introduction of C. micronesica plants into a karst habitat generated decreases in soil phosphorus after five years and increases in soil nitrogen after six years. The carbon:nitrogen:phosphorus stoichiometry beneath the cycad plants significantly diverged from those of the adjacent native forests with Pisonia grandis, Psychotria mariana, Aglaia mariannensis, Cynometra ramiflora, and Ficus sp. cover after five years. Mineralization traits were determined beneath nine-year-old C. micronesica plants and revealed the plants greatly increased net nitrification and decreased net ammonification when compared to the native forest soils with Bursera simaruba, Pinus elliottii, and Quercus virginiana cover. These flux changes increased the total available nitrogen and percent available nitrogen in the soils beneath the cycad plants. The substrates of two soil series exhibited increased carbon and nitrogen concentrations beneath Z. integrifolia plants when compared with soils away from the cycad plants. No other mineral or metal was influenced by proximity to the Z. integrifolia plants. These gymnosperms exhibit distinct interactions with their subtending soils, and some of these traits improve ecosystems by increasing recalcitrant carbon and nitrogen and increasing spatial heterogeneity of soil chemistry.
\end{abstract}

Keywords: cycad; Cycas micronesica; litter-trapping plants; stemflow; Zamia integrifolia

\section{Introduction}

Perennial plants may alter the physical and chemical properties of soils over time due to their sessile nature. These traits may shape biogeochemical processes of the communities in which they live, thereby influencing ecosystem spatial heterogeneity [1,2]. The direct influence of the gymnosperm Cycas micronesica K.D. Hill (Cycadaceae, Cycadales) on soil chemistry was determined in a variety of locations and soils [3]. The results revealed an increase in nitrogen and carbon and a decrease in phosphorus in the soils beneath the in situ cycad trees. The arborescent $C$. micronesica is found in the United States (U.S.) territorial island of Guam and the U.S. Commonwealth island of Rota. Another U.S. cycad species is the diminutive Zamia integrifolia L.f. (Zamiaceae, Cycadales), which is the only cycad species that is native to the conterminous U.S. [4,5].

Enhanced conservation knowledge is especially needed for C. micronesica, which has been listed as endangered since 2006 [6]. Various in situ and ex situ conservation projects have been initiated and include a germplasm collection from Guam-sourced seeds that was planted in 2008 on the U.S. Commonwealth island of Tinian $[7,8]$. Soil samples were collected from the germplasm site during various years from 2008 to 2018 to understand how the introduction of the cycad plants to the native limestone forest habitat modified various attributes of the karst soils. Herein we focused on those 
modifications in nitrogen, carbon, and phosphorus and the carbon:nitrogen:phosphorus stoichiometric traits. Moreover, the long list of minerals and metals that were determined in the earlier C. micronesica report [3] did not include labile biogeochemical variables such as the components of mineralization. We used this managed Tinian C. micronesica germplasm to determine the ephemeral changes in ammonium and nitrate and how the introduced cycad trees influenced these mineralization processes.

We also included Z. integrifolia in this report to expand the list of studied cycad taxa to two species, and because it is commonly used in the nursery and landscape horticulture industry. Our approach was to repeat the methods that were previously used for C. micronesica [3]. Because cycad roots associate with nitrogen-fixing endosymbionts, we predicted the changes in soil nitrogen concentrations associated with the newly introduced cycad plants would begin earlier than the changes in soil carbon or phosphorus. Furthermore, we predicted significant changes in nitrogen mineralization traits in close proximity to the cycad trees. Because Z. integrifolia plants are small and the spatial patterns included mostly solitary plants, we predicted any significant changes in soil chemistry would be in the same direction but more muted than what was reported for the arborescent $C$. micronesica.

\section{Materials and Methods}

\subsection{Cycas micronesica}

The experimental site for our Cycas micronesica study was the island of Tinian in karsty outcrop soils (loamy-skeletal, carbonatic, isohyperthermic Lithic Haplustolls) [9]. The site was a managed ex situ germplasm collection of C. micronesica plants originating from localities throughout Guam. The plants were two years old when they were initially transplanted from a container nursery in 2008, and plant density was 1100 plants per ha. There were 16 disjunct plots positioned on a north-south gradient of $950 \mathrm{~m}$, and soil samples were collected from the plots from 2008 until 2018. The initial soil cores were collected in August 2008, and subsequent collections were in April of 2012, 2013, 2014, 2017, and 2018.

\section{Experimental Design and Sampling}

The fieldwork and analyses were patterned after our previous methods [3,8]. The soils associated with the C. micronesica plants were collected at half the length of the pinnately compound leaves, and four subsample cores at each cardinal direction were collected in the $0-10 \mathrm{~cm}$ horizon for each specimen. The collection of soil cores from a paired site located $10 \mathrm{~m}$ within the adjacent undisturbed native forest was patterned in conformity with the four subsample sites around each cycad plant for each year. The dominant tree species in the native forest were Pisonia grandis R.Br., Psychotria mariana Bart. ex DC., Aglaia mariannensis Merr., Cynometra ramiflora L., and Ficus L. sp.

Two paired sampling sites were collected from each plot, and the cores from plots 1-4, 5-8, 9-12, or 13-16 were combined into one homogenized sample to create four paired replications for each year (Figure 1). Therefore, the soil samples representing each replication were comprised of four cores around each of two sites per plot and four plots for a total of 32 homogenized cores. The four paired replications were based on a total of 256 soil cores for each year. The soils associated with the C. micronesica plants are referred to as "cycad" hereinafter, and the soils from the paired forest locations are referred to as "native" hereinafter. 


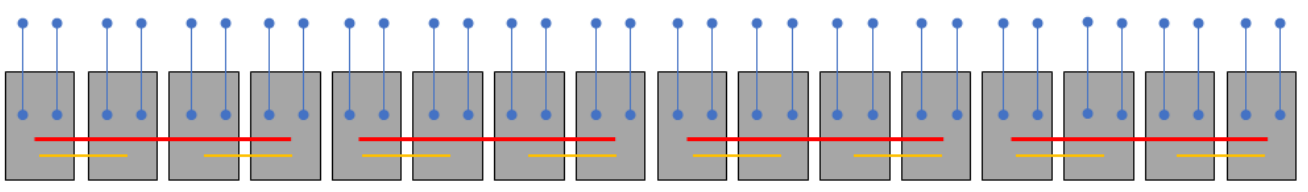

Figure 1. Schematic of the Cycas micronesica plot and sampling layout. Each gray rectangle represents one of 16 ex situ plots with a mean of $\sim 50$ plants each. Blue dots represent soil sampling sites, with each comprised of four cores. Each plot contained two paired sampling sites, one inside and one outside the plot. Red bars connect the plots that were combined to create four replications for carbon, nitrogen, and phosphorus quantification. Yellow bars connect the plots that were combined to create eight replications for mineralization study.

\subsection{Zamia integrifolia}

We surveyed Zamia integrifolia L.f. populations in four locations in Dade County, Florida. One Coral Gables site was positioned within the Montgomery Botanical Center $\left(25^{\circ} 39.626^{\prime}, 80^{\circ} 16.881^{\prime}\right)$ and a second site was nearby on private property. The emergent canopy for these sites was comprised of Bursera simaruba (L.) Sarg., Pinus elliottii Engelm., and Quercus virginiana Mill. These locations were sampled on 23 May 2018, and the soils were sandy, siliceous, hyperthermic Lithic Udorthents. One Homestead site was positioned within the University of Florida Tropical Research and Education Center $\left(25^{\circ} 30.424^{\prime}, 80^{\circ} 30.303^{\prime}\right)$ and a second site nearby on private property. The emergent canopy was exclusively P. elliottii, the locations were sampled on 26 May 2018, and the soils were loamy-skeletal, carbonatic, hyperthermic Lithic Udorthents. Both of these soils are subtended by hard porous limestone bedrock, and they are located within the Everglades Flatwoods ecological plant community [10]. All collection sites were within relatively small but intact forest fragments in urban or agriculture complexes.

The pinnately compound leaves of this species may reach lengths of $91 \mathrm{~cm}$ [11]. The leaves of our study plants were not this long, and target soils were collected at half the length of each plant's leaves. Four subsamples were collected from the $0-10 \mathrm{~cm}$ horizon in the direction of each cardinal point then combined to create one "cycad" replication. The native forest soils were collected in a ring of $3 \mathrm{~m}$ radius surrounding each target plant, and four soil subsamples were obtained from the four cardinal points on the ring then combined into one "native" replication.

\subsection{Chemical Analyses}

Total carbon and nitrogen contents were determined by dry combustion for both studies (FLASH EA1112 CHN analyzer; Thermo Fisher, Waltham, MA, USA). Available P was extracted by the Olsen method [12] and analysis was by inductively coupled plasma optical emission spectrometry for both studies (Spectro Genesis; SPECTRO Analytical Instruments, Kleve, Germany).

Mineralization traits were determined from the C. micronesica cores harvested in 2017. In order to increase the replication number for this one-time analysis, the cores from every two sequential plots (south to north) were combined for a total of 8 replications along the north-south gradient. Nitrate and ammonium were determined colorimetrically before and after a 30-day incubation following $2 \mathrm{M}$ potassium chloride extraction [13]. The incubation was accomplished using the buried bag method [14]. Nocturnal low temperatures were $23-24{ }^{\circ} \mathrm{C}$ and the diurnal high temperatures were $33-25^{\circ} \mathrm{C}$ for the incubation period. Total nitrogen of the before and after samples was determined by dry combustion as described above. Net nitrification flux was calculated as (end nitrate - initial nitrate) / incubation duration. Net ammonification flux was calculated as (end ammonium - initial ammonium)/incubation duration. Net mineralization was calculated as nitrification + ammonification. Total available nitrogen was calculated as initial nitrate + initial ammonium. Percent available nitrogen was calculated as (available nitrogen/total nitrogen) $\times 100$. The relative nitrification rate was calculated as (net nitrification/mineralization) $\times 100$. Extractable essential minerals were digested from the Z. integrifolia 
soils with diethylenetriaminepentaacetic acid, and total metals were digested from these soils with nitric acid $[15,16]$. The analysis was by inductively coupled plasma optical emission spectrometry.

\subsection{Statistics}

The influences of two soil types over seven years on nitrogen, carbon, and phosphorus concentrations were assessed for the long-term C. micronesica study using repeated measures analysis of variance with four replications. The year was designated as the repeated measure and the analysis used an autoregressive covariance structure (PROC MIXED; SAS Institute, Cary, NC, USA). Means separation for significant factors was conducted using the Tukey's HSD test.

All response variables for the $C$. micronesica mineralization study and the Z. integrifolia study were subjected to a paired $t$-test to determine differences between cycad and native soils. There were eight paired replications for the $C$. micronesica study, with each replication comprised of two adjacent ex situ plots. There were six paired replications from each of the soil series in the Z. integrifolia study, with each replication comprised of four subsamples for a total of 48 soil cores for each of the soils. The data from each soil series were analyzed separately.

\section{Results}

\subsection{Cycas micronesica}

The chronic presence of $C$. micronesica plants in the Tinian karst forest habitat influenced soil nitrogen, carbon, and phosphorus in a dissimilar manner. The soil type $(p<0.001)$, year $(p<0.001)$, and soil type $\times$ year $(p=0.006)$ factors were significant for nitrogen concentration. Nitrogen concentration beneath the cycad plants increased above that of the native forest by 2014 (Figure 2a), then continued to increase until the end of the study in 2018. The soils beneath the cycad plants exhibited a nitrogen concentration that was 33\% greater than the soils in the native forest following 10 years of plant growth. The patterns of carbon concentrations varied more so than nitrogen (Figure 2b), and the soil type $(p=0.261)$, year $(p=0.851)$, and soil type $\times$ year $(p=0.368)$ factors were not significant. An arithmetic increase in carbon occurred in the final two years of the study, but the differences were not significant due to the substantial variability among the samples and years. The soil type $(p<0.001)$, year $(p<0.001)$, and soil type $\times$ year $(p=0.026)$ factors were significant for phosphorus. Phosphorus concentration beneath the cycad plants decreased below that of the native forest by 2013 (Figure 2c). Available phosphorus beneath the cycad plants was only $35 \%$ of that within the adjacent native forest by 2018.

The carbon:nitrogen:phosphorus stoichiometry traits followed patterns as predicted from the individual element concentrations. Carbon/nitrogen was not influenced by the soil type $\times$ year interaction $(p=0.672)$, but the soil type $(p=0.045)$ and year $(p=0.002)$ main effects were significant. Carbon/nitrogen declined as the study progressed, and the soils beneath the cycad plants exhibited values that were generally less than those of soils in the native forest (Figure 2d). The increases of carbon and nitrogen tracked closely enough that carbon/nitrogen was not significant among the sources of variation. Carbon/phosphorus was influenced by the soil type $(p<0.001)$, year $(p<0.001)$, and soil type $\times$ year $(p<0.001)$. Carbon/phosphorus of the soils beneath the cycad plants exceeded that of the soils in the native forest by 2014, and continued to increase with each subsequent year (Figure 2e). Carbon/phosphorus beneath the cycad plants was 2.4-fold greater than beneath the native forest by 2018. Nitrogen/phosphorus was influenced by the soil type $(p<0.001)$, year $(p<0.001)$, and soil type $\times$ year $(p<0.001)$. Nitrogen/phosphorus of the soils beneath the cycad plants exceeded that of the soils in the native forest by 2013, and continued to increase with each subsequent year (Figure 2f). Nitrogen/phosphorus beneath the cycad plants was 2.7-fold greater than beneath the native forest by 2018 . 

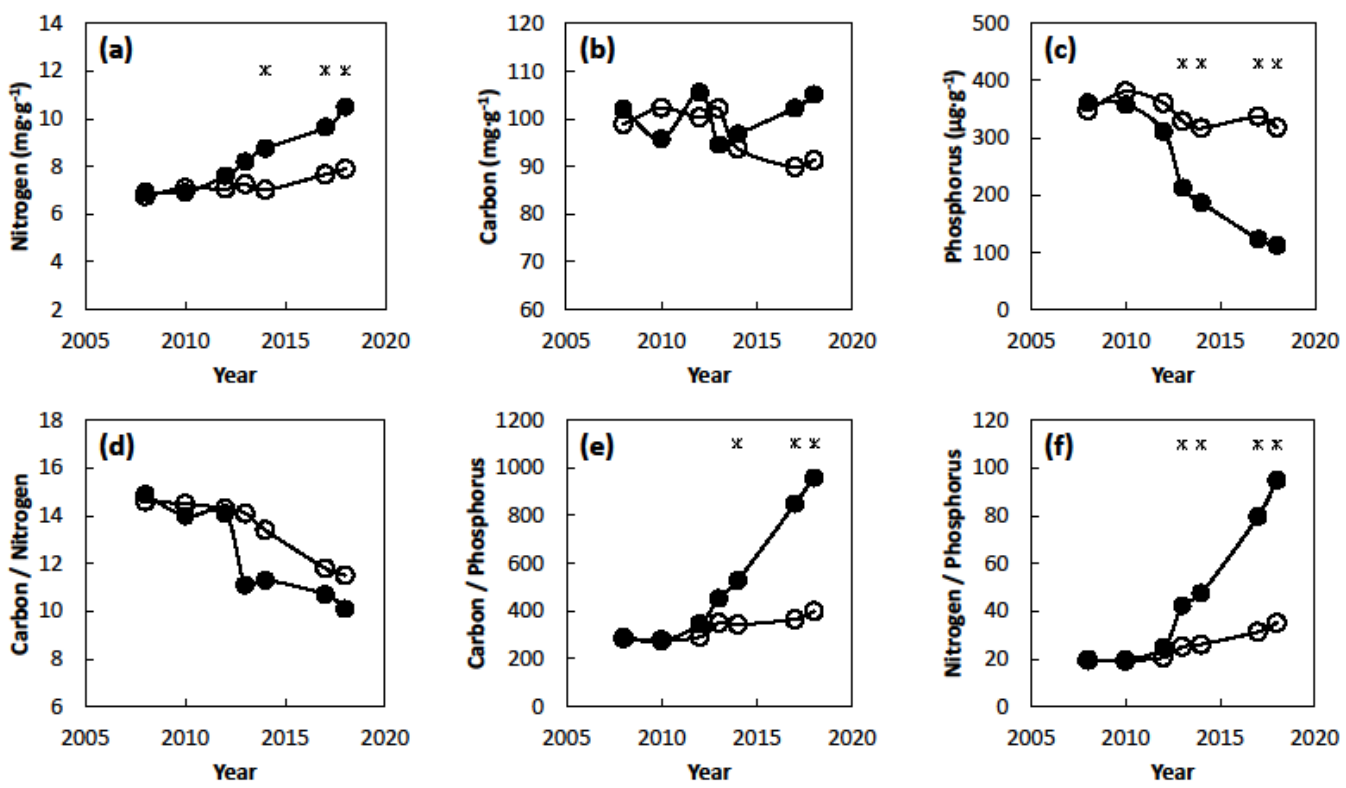

Figure 2. The influence of soil type and years since planting of Cycas micronesica plants in Tinian on soil chemistry. Closed circles = soils beneath cycad plants, open circles = soils beneath adjacent native forest. (a) Total nitrogen concentration; (b) total carbon concentration; (c) available phosphorus concentration; (d) carbon/nitrogen; (e) carbon/phosphorus; (f) nitrogen/phosphorus. ${ }^{*}=$ significant difference between soil type, $\mathrm{n}=4)$.

Nitrogen mineralization traits were greatly altered by the presence of $C$. micronesica plants in the Tinian karst native forest. The 2017 samples represented soils that were imprinted with the cycad plants for nine years. The cycad soils exhibited a $56 \%$ increase in total nitrogen, a $24 \%$ increase in nitrate, and a $49 \%$ increase in ammonium when compared with soils in the adjacent native forest (Figure 3). Net nitrification flux increased $55 \%$ and net ammonification flux decreased $92 \%$ in the cycad soils when compared with the native soils. Relative nitrification increased $26 \%$ in the cycad soils when compared with the native soils. Total available nitrogen was influenced by the cycad plants $(t=3.278, p=0.006)$, with native forest soils exhibiting $69.3 \pm 3.3 \mu \mathrm{g} \cdot \mathrm{g}^{-1}$ and the cycad soils exhibiting $98.6 \pm 8.3 \mu \mathrm{g} \cdot \mathrm{g}^{-1}$. The percentage of nitrogen that was in available forms was also influenced by the cycad plants $(t=2.226, p=0.043)$, with native forest soils exhibiting $1.8 \% \pm 0.3 \%$ and the cycad soils exhibiting $1.2 \% \pm 0.2 \%$. Net mineralization flux was not influenced by the cycad plants $(t=1.382$, $p=0.188)$, because the increase in nitrification beneath the cycad plants canceled the decrease in ammonification (data not shown).

\subsection{Zamia integrifolia}

The soil nitrogen concentration near the Z. integrifolia plants in the sand substrate was more than triple that of the native forest cover, and the carbon concentration near the Z. integrifolia plants was more than double that of the native forest cover (Figure 4). The soil nitrogen concentration near the $Z$. integrifolia plants in the loam substrate was $27 \%$ greater than nitrogen in the native forest cover, and the carbon concentration near the Z. integrifolia plants was $23 \%$ greater than carbon in the native forest cover. 

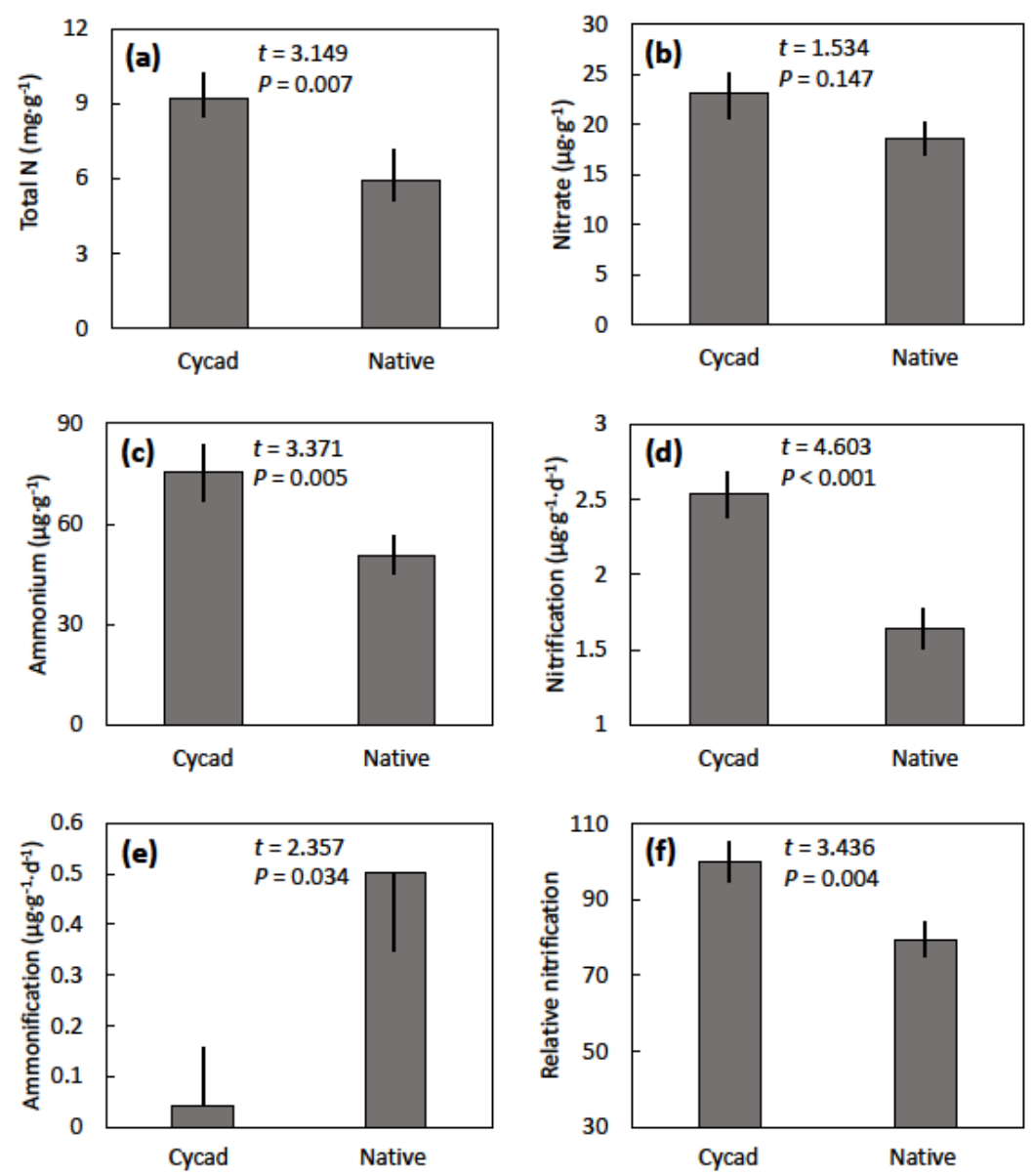

Figure 3. The influence of Cycas micronesica plants (cycad) and native forest (native) on soil nitrogen mineralization. (a) Total nitrogen concentration; (b) nitrate concentration; (c) ammonium concentration; (d) net nitrification (e) net ammonification; (f) relative nitrification. Means \pm standard error, $\mathrm{n}=8$.
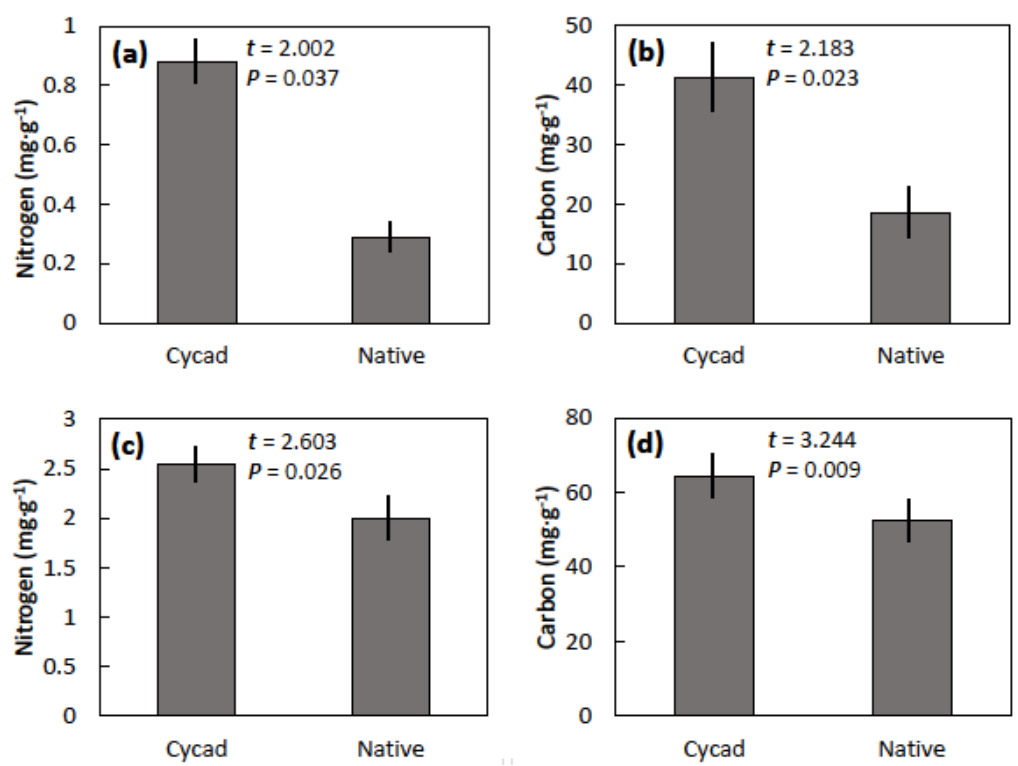

Figure 4. The influence of Zamia integrifolia plants (cycad) and native forest (native) on soil nitrogen and carbon. (a) Sand soil total nitrogen; (b) sand soil total carbon; (c) loam soil total nitrogen; (d) loam soil total carbon. Means \pm standard error, $n=6$. 
The soil $\mathrm{pH}$, edaphic essential elements other than nitrogen, and metals were not influenced by proximity to the Z. integrifolia plants in either soil type (Table 1). With the exception of iron, lead, and selenium, the elemental concentrations in the loam soil greatly exceeded those in the sandy soil.

Table 1. The influence of proximity to Zamia integrifolia plants on soil chemical traits in Florida sand or loam soils. Soil traits were not significant by $t$-test. Means \pm standard error, $n=12$, units $=\mu g^{-1}$.

\begin{tabular}{ccccc}
\hline Soil Trait & Sand & Sand Significance & Loam & Loam Significance \\
\hline pH & $6.88 \pm 0.09$ & 0.164 & $7.22 \pm 0.05$ & 0.100 \\
Phosphorus & $5.44 \pm 0.32$ & 0.981 & $6.91 \pm 0.25$ & 0.827 \\
Potassium & $30.35 \pm 3.43$ & 0.139 & $191.35 \pm 18.75$ & 0.343 \\
Calcium & $2516.53 \pm 515.02$ & 0.507 & $5773.33 \pm 189.88$ & 0.808 \\
Magnesium & $115.69 \pm 23.61$ & 0.375 & $351.99 \pm 22.80$ & 0.100 \\
Manganese & $3.86 \pm 0.63$ & 0.717 & $34.47 \pm 3.10$ & 0.087 \\
Iron & $44.58 \pm 4.80$ & 0.653 & $33.78 \pm 2.12$ & 0.209 \\
Cobalt & $0.16 \pm 0.02$ & 0.942 & $4.07 \pm 0.08$ & 0.093 \\
Chromium & $4.40 \pm 0.49$ & 0.355 & $126.23 \pm 2.79$ & 0.649 \\
Copper & $1.29 \pm 0.08$ & 0.944 & $16.91 \pm 0.98$ & 0.409 \\
Nickel & $1.02 \pm 0.11$ & 0.620 & $17.37 \pm 0.54$ & 0.410 \\
Lead & $12.07 \pm 1.84$ & 0.417 & $10.58 \pm 1.49$ & 0.774 \\
Selenium & $1.87 \pm 0.43$ & 0.321 & $0.99 \pm 0.24$ & 0.629 \\
Zinc & $20.88 \pm 3.82$ & 0.694 & $39.71 \pm 6.57$ & 0.639 \\
\hline
\end{tabular}

\section{Discussion}

\subsection{The Two Species}

The trajectories of the changes in soil nitrogen, carbon, and phosphorus concentrations during the 10 years following the introduction of $C$. micronesica plants to a native karst forest site were in the direction of the published findings on mature, established in situ plants [3]. We predicted the changes in soil nitrogen in response to the introduced C. micronesica plants would occur prior to the changes in soil carbon or phosphorus. The results did not conform to this prediction, as the decline in phosphorus concentration in the soils associated with the $C$. micronesica plants occurred by year five and preceded the increases in nitrogen or carbon concentration. This rapid change in soil phosphorus also caused significant changes in carbon:nitrogen:phosphorus stoichiometry. The results indicated that C. micronesica plants out-compete sympatric native trees for available phosphorus, and this phosphorus is presumably sequestered in the cycad organs.

Cycad plants associate with nitrogen-fixing cyanobacteria in specialized roots [5]. The increases in soil nitrogen in close proximity to the C. micronesica and Z. integrifolia plants illuminated one of the manners by which cycad plants improve ecosystem health by contributing the nitrogen that is originally fixed in their roots to the surrounding edaphic substrates over time. While available nitrogen increased beneath the $C$. micronesica plants, this labile form of nitrogen accounted for less than $2 \%$ of the total nitrogen. These findings indicated that cycad plants contribute a copious amount of recalcitrant nitrogen to their soils.

The 55\% increase in net nitrification that we encountered in the soils beneath the C. micronesica trees when compared with the native forest soils indicated that these cycad plants increased abundance and/or activity of Nitrosomonas and Nitrobacter microbes, which are responsible for the conversion of ammonium to nitrate [17]. These observations revealed one of the improvements that cycad plants contribute to their habitats: the spatial heterogeneity in edaphic chemistry provides niche habitats for other organisms to exploit. We presumed the Nitrosomonas and Nitrobacter that colonized the niche soils beneath the cycad plants were native species from the in situ Tinian soils or vectored in the C. micronesica seeds from Guam. We did not introduce any alien soils with the C. micronesica seeds from Guam. 
The changes of Z. integrifolia plants on soil nitrogen and carbon were in the same direction as C. micronesica [3], which conformed to our prediction. The percentage change in the sand soils was substantial, so these changes were as great as the changes in most of the C. micronesica soils. The percentage change in the sand soils greatly exceeded that in the loam soils. This observation corroborated the findings with C. micronesica, in that the direction of change in nitrogen and carbon was consistent, but the percentage change varied greatly among five soil types [3]. These results revealed the need to study cycad species in all habitat types throughout their native range, as the experimental or observational results from one habitat may not accurately apply to other habitats.

The relative influence of cycad plants on the soil minerals and metals contrasted sharply between the C. micronesica report [3] and our Z. integrifolia data herein. Mature C. micronesica trees generated significant changes in many soil minerals and metals, primarily in the acid and sand substrates. In contrast, the Z. integrifolia plants did not influence the concentration of any mineral or metal other than nitrogen. Differences in taxonomy, mature plant size, transfer of elements through stemflow, and the ability to trap litter are among the potential mitigating factors that may explain the differences between the two species. These factors are further discussed below.

The sand Z. integrifolia soils were impoverished compared to the loam Z. integrifolia soils. Moreover, both of these soils exhibited critically low phosphorus concentrations. Interspecific competition for phosphorus may be one of the abiotic stressors within in situ Z. integrifolia localities, a subject that deserves further study.

\subsection{Future Directions}

A greater understanding of how these two U.S. cycad species influence edaphic traits in their habitats would improve horticultural and conservation decisions and expand general knowledge of this important gymnosperm order. Our collective results point toward several areas of needed research. Continued work in these directions would contribute greatly to the various ecology subdisciplines but also to cycad biology and conservation.

Firstly, our contrasting results for the two species may have been under genetic control. Indeed, the branching process initiating Cycas occurred hundreds of millions of years before the branching process initiating Zamia [18]. The phylogenetic and taxonomic level of understanding of the Cycadales continues to improve, with 356 accepted species descriptions as of this report [19].

Secondly, our two species were also highly contrasting in mature plant size, so an allometric factor may have mediated our results. The studied $C$. micronesica plants were restricted to individuals with stems greater than $3 \mathrm{~m}$ in height, representing substantial sequestration potential among the large organs. In contrast, the Z. integrifolia plants were universally less than $15 \mathrm{~cm}$ in stem height, indicating a comparably small plant body for the storage of inorganic resources.

Third, rainfall rarely reaches the soil surface without first being intercepted by plant structures. This intercepted rainfall is lost through evaporation or transferred to the soil as throughfall or stemflow. The relative proportions of these processes are influenced by canopy and leaf traits, and strongly influence the spatial components of the hydrologic and chemical cycles beneath mixed stands of plants [20-24]. To our knowledge, no studies of stemflow have included a cycad representative. The inclusion of a range of cycad taxa in the stemflow research agenda would add greatly to our knowledge of how cycad plants directly affect soil chemistry, but would also improve our understanding of carbon, hydrologic, and nitrogen cycles by adding this unique gymnosperm plant group to the stemflow literature.

Fourth, some plants may influence the biogeochemical cycle by litter trapping. The leaf and stem traits of these plants increase the volume of litterfall that is trapped in the plant's canopy, and this trapped litter becomes a privatized slow compost pile that releases nutrients over time [25]. As with stemflow, we are not aware of any cycad taxa that have been studied for litter-trapping abilities. 


\subsection{Conclusions}

We have shown that the addition of a C. micronesica plant to a forest habitat may begin to alter the localized soil carbon:nitrogen:phosphorus stoichiometry after only five years of growth. We have also added new knowledge concerning the nitrogen cycle by showing that $C$. micronesica plants greatly increase net nitrification and decrease net ammonification of soils beneath their canopy. The substrates of two soil series exhibited increased carbon and nitrogen concentrations beneath Z. integrifolia plants when compared with soils away from the cycad plants. Two cycad species have been shown to deliver unique soil chemistry properties to their habitats and improve ecosystem health by increasing spatial heterogeneity of soil chemistry.

Author Contributions: Conceptualization, T.E.M. and M.C.; methodology, T.E.M. and M.C.; formal analysis, T.E.M.; resources, M.C.; writing-original draft preparation, T.E.M. and M.C. All authors have read and agreed to the published version of the manuscript.

Funding: This research was funded by the United States Forest Service grant numbers 09-DG-11052021-173 and 13-DG-11052021-210; and the United States Department of the Navy Cooperative Agreement numbers N40192-12-2-8000, N40192-16-M-5006, and N40192-17-P-5009.

Acknowledgments: We thank Patrick Griffith and Bruce Schaffer for facilitating access to the collection sites.

Conflicts of Interest: The authors declare no conflict of interest.

\section{References}

1. Crocker, R.L.; Major, J. Soil development in relation to vegetation and surface age at Glacier Bay, Alaska. J. Ecol. 1955, 43, 427-448. [CrossRef]

2. Kelly, E.F.; Chadwick, O.A.; Hilinski, T.E. The effects of plants on mineral weathering. Biogeochemistry 1998, 42, 21-53. [CrossRef]

3. Marler, T.E.; Krishnapillai, M.V. Cycas micronesica trees alter local soil traits. Forests 2018, 9, 565. [CrossRef]

4. Hill, K.D. The Cycas rumphii complex (Cycadaceae) in New Guinea and the Western Pacific. Aust. Syst. Bot. 1994, 7, 543-567. [CrossRef]

5. Norstog, K.J.; Nicholls, T.J. The Biology of the Cycads; Cornell University Press: Ithaca, NY, USA, 1997; ISBN 978-0-8014-3033-6.

6. Marler, T.; Haynes, J.; Lindström, A. 2010 Cycas micronesica. IUCN 2012. IUCN Red List of Threatened Species. e.T61316A12462113. Available online: www.iucnredlist.org (accessed on 28 February 2020).

7. Anonymous. Conserving our nation's only native cycad species. Currents 2014, Fall, $28-31$.

8. Marler, T.E.; Dongol, N.; Cruz, G.N. Leucaena leucocephala and adjacent native limestone forest habitats contrast in soil properties on Tinian Island. Commun. Integr. Biol. 2016, 9, e1212792. [CrossRef] [PubMed]

9. Young, F.J. Soil Survey of the Islands of Aguijan, Rota, Saipan, and Tinian, Commonwealth of the Northern Mariana Islands; United States Department of Agriculture, Soil Conservation Service: Washington, DC, USA, 1989.

10. Noble, C.V.; Drew, R.W.; Slabaugh, J.D. Soil Survey of Dade County Area, Florida; United States Department of Agriculture Natural Resources Conservation Service: Washington, DC, USA, 1996.

11. Whitelock, L.M. The Cycads; Timber Press: Portland, OR, USA, 2002.

12. Olsen, S.R.; Cole, C.V.; Watanabe, F.S.; Dean, L.A. Estimationof Available Phosphorus in Soils by Extraction with Sodium Bicarbonate; United States Department of Agriculture, Circular939, U.S. Government Printing Office: Washington, DC, USA, 1954.

13. Cataldo, D.A.; Haroon, M.; Schrader, L.E.; Youngs, V.L. Rapid colorimetric determination of nitrate in plant tissue by nitration of salicylic acid. Commun. Soil Sci. Plant Anal. 1975, 6, 71-80. [CrossRef]

14. Eno, C.F. Nitrate production in the field by incubating the soil in polyethylene bags. Proc. Soil Sci. Soc. Am. 1960, 24, 277-279. [CrossRef]

15. Berghage, R.D.; Krauskopf, D.M.; Warncke, D.D.; Widders, I. Micronutrient testing of plant growth media extractant, identification and evaluation. Commun. Soil Sci. Plant Anal. 1987, 18, 1089-1109. [CrossRef]

16. Zheljazkov, V.D.; Warman, P.R. Comparison of three digestion methods for the recovery of 17 plant essential nutrients and trace elements from six composts. Compost Sci. Utiliz. 2002, 10, 197-203. [CrossRef]

17. Schimel, J.P.; Bennett, J. Nitrogen mineralization: Challenges of a changing paradigm. Ecology 2004, 85, 591-602. [CrossRef] 
18. Condamine, F.L.; Nagalingum, N.S.; Marshall, C.R.; Morlon, H. Origin and diversification of living cycads: A cautionary tale on the impact of the branching process prior in Bayesian molecular dating. BMC Evol. Biol. 2015, 15, 65. [CrossRef] [PubMed]

19. Calonje, M.; Stevenson, D.W.; Osborne, R. The World List of Cycads. Available online: http://cycadlist.org (accessed on 28 February 2020).

20. Levia, D.F., Jr.; Frost, E.E. A review and evaluation of stemflow literature in the hydrologic and biogeochemical cycles of forested and agricultural ecosystems. J. Hydrology 2003, 274, 1-29. [CrossRef]

21. Levia, D.F.; Germer, S. A review of stemflow generation dynamics and stemflow-environment interactions in forests and shrublands. Rev. Geophys. 2015, 53, 673-714. [CrossRef]

22. Van Stan, J.T.; Gordon, D.A. Mini-review: Stemflow as a resource limitation to near-stem soils. Front. Plant Sci. 2018, 9, 248. [CrossRef] [PubMed]

23. Su, L.; Zhao, C.; Xu, W.; Xie, Z. Hydrochemical fluxes in bulk precipitation, throughfall, and stemflow in a mixed evergreen and deciduous broadleaved forest. Forests 2019, 10, 507. [CrossRef]

24. Dunkerley, D. A review of the effects of throughfall and stemflow on soil properties and soil erosion. In Precipitation Partitioning by Vegetation; Van Stan, J., II, Gutmann, E., Friesen, J., Eds.; Springer: Cham, Switzerland, 2020; pp. 183-214.

25. Zona, S.; Christenhusz, M.J.M. Litter-trapping plants: Filter-feeders of the plant kingdom. Bot. J. Linnean Soc. 2015, 179, 554-586. [CrossRef]

(C) 2020 by the authors. Licensee MDPI, Basel, Switzerland. This article is an open access article distributed under the terms and conditions of the Creative Commons Attribution (CC BY) license (http://creativecommons.org/licenses/by/4.0/). 